\title{
Bankruptcy Prediction Model Using Neural Networks
}

\author{
Xavier Brédart ${ }^{1}$ \\ ${ }^{1}$ Warocqué School of Business and Economics, University of Mons, Mons, Belgium \\ Correspondence: Xavier Brédart, Warocqué School of Business and Economics, University of Mons, Place Warocqué, \\ 17, 7000, Mons, Belgique. Tel: 32-0-6537-3213. E-mail: xavier.bredart@umons.ac.be
}

Received: April 3, 2014

Accepted: April 15, 2014

Online Published: April 17, 2014

doi:10.5430/afr.v3n2p124

URL: http://dx.doi.org/10.5430/afr.v3n2p124

\begin{abstract}
Belgium has faced an important number of corporate bankruptcies during the last decade. The aim of this paper is to develop a model that predicts bankruptcy using three financial ratios that are simple and easily available, even for small businesses. We used a sample of 3,728 Belgian Small and Medium Enterprises (SME's) including 1,864 businesses having been declared bankrupt between 2002 and 2012 and conducted a neural network analysis. Our results indicate that the neural network methodology based on three financial ratios that are simple and easily available as explanatory variables shows a good classification rate of more or less 80 percent. Results of this study may be of interest for financial institutions and for academics.
\end{abstract}

Keywords: Bankruptcy, Neural network, Prediction model

\section{Introduction}

In recent years, Belgium faces many cases of corporate bankruptcies. Financial distress is a topic that interests many actors (Daubie \& Meskens, 2001) such as investors and shareholders, lawmakers, central banks, auditors and managers.

In this context, the theme of business failure has attracted the attention of researchers for many years. Studies regarding bankruptcy prediction generally aim to determine one or several variable(s) that make it possible to discriminate between bankrupt and healthy businesses (Refait, 2004). The pioneers are called Beaver (1966) and Altman (1968) using univariate and linear discriminant analyses, respectively. More recently, studies using different statistical techniques have been led such as Logit (Ohlson, 1980) and Probit models (Zmijewski, 1984). However, statistical methods depend on restrictive hypotheses. In the nineties, thanks to the evolution of computer sciences, some authors have had the idea to resort to artificial intelligence algorithms such as neural networks (Odom \& Sharda, 1990; Altman et al., 1994; Hu et al., 1999; Platt et al., 1999; Lee, 2001; Alam et al., 2005; Hu \& Tseng, 2010; Kim \& Kang, 2010). Murtaza \& Shah (2000) use a neural network to predict bankruptcy of US firms between 1992 and 1994 using 9 ratios; they report a good classification rate of 73 percent. Also using neural networks, the study of Abou-Seada et al. (2005), led on British corporations between 1997 and 2000, reports a good classification rate of 83 percent using 5 ratios.

Few models dedicated to bankruptcy prediction applied to the Belgian case (Ooghe \& Verbaere, 1982; Declerc et al., 1992; Ooghe et al., 2005). None of these use artificial intelligence. In this context, this article will help to fill this gap on the Belgian literature relative to bankruptcy via the setting up of a neural network.

The aim of this paper is to build a "user friendly" bankruptcy prediction model using three simple and easily accessible ratios. To this end, we conduct a neural network analysis upon a sample of 3,728 Belgian SME's among which 1,854 were declared bankrupt between 2002 and 2012. A neural network is then built to determine the probability that bankruptcy occurs for a business. An important part of the setting of the neural network is related to the selection of discriminant financial ratios. Solvency, liquidity and profitability ratios show very high discriminating power (Refait, 2004) regarding bankruptcy prediction. More precisely, we will use the following ratios that are used in many studies aiming to predict bankruptcy (Akers, et al., 2007) to train our neurons: total equity/total assets for solvency, current ratio for liquidity and EBIT/total assets for profitability ratio. We hypothesize that these ratios are variables that allow discriminating between bankrupt and healthy businesses. Variables that are introduced into the model are recorded the year before the potential bankruptcy filing. 
The results of our study show that these three ratios are good predictors of bankruptcy. The good classification rate of this tool is higher than $80 \%$ for the bankrupt businesses. Moreover, the ratios that are used to train the neural network are simple and easily available, even for small businesses. This study may be of interest for financial institutions who are interested by the potential bankruptcy of their clients. Academics may also be interested by the results of this study because the methodology that is used is uncommon in the Belgian literature regarding bankruptcy prediction.

The paper proceeds as follows. In section 2, we detail our sample and the methodology used to predict bankruptcy. Section 3 concerns descriptive statistics and results of the neural network. Section 4 will discuss the results and highlights the main conclusions of this research.

\section{Methodology}

\subsection{Sample and data}

For this study, we used a sample of 3,728 Belgian Small and Medium Enterprises (SME's) including 1,864 businesses having been declared bankrupt between 2002 and 2012 and conducted a neural network analysis. The Belfirst database (Bureau Van Dijk) has been utilized to collect all the information regarding this sample of businesses. We first selected bankrupt businesses for which we had enough information for our analysis. In a second step, we randomly selected "healthy" businesses among the entire list of businesses of the Belfirst database (Bureau Van Dijk). We finally collected accounting information on Belfirst database (Bureau Van Dijk).

\subsection{Measures}

Because we aim to explain the bankruptcy probability of businesses, we utilize, as dependent variable, a binary variable as it is the case in many studies about bankruptcy prediction such as the ones of Olhson (1980) or Bhabra et al. (2009). The name of our dependent variable is Bankruptcy. This variable takes the value 1 if the business has been declared bankrupt between 2002 and 2012 and 0 otherwise.

The neural network accounts for three explanatory variables. These are the solvency, the liquidity and the profitability of the businesses. Solvency is defined as the ratio total equity/total assets on the latest accounting fiscal year before bankruptcy. Liquidity is reflected by the current ratio on the latest accounting fiscal year before bankruptcy. Finally, profitability refers to the ratio net income/total assets on the latest accounting fiscal year before bankruptcy.

\subsection{Methodology}

An artificial neural network is layered; each of these layers has several neurons that are connected to other neurons belonging to the preceding and following layer. Figure 1 show neurons arranged in three layers, an input layer, a hidden layer and output layer. The numbers of neurons of the input and output layers are respectively equal to the number of variables presented simultaneously to the network and to the number of variables that the neural network must estimate. In the case of bankruptcy prediction on the basis of solvency, liquidity and profitability ratios, the number of variables presented to the network is equal to 3 and the single variable to be estimated is the bankruptcy of the company. The output neuron takes the value 0 if the company is healthy and 1 if it is bankrupt. Neurons are connected together via synaptic weights $\mathrm{W}$ which are incrementally estimated during the learning phase.

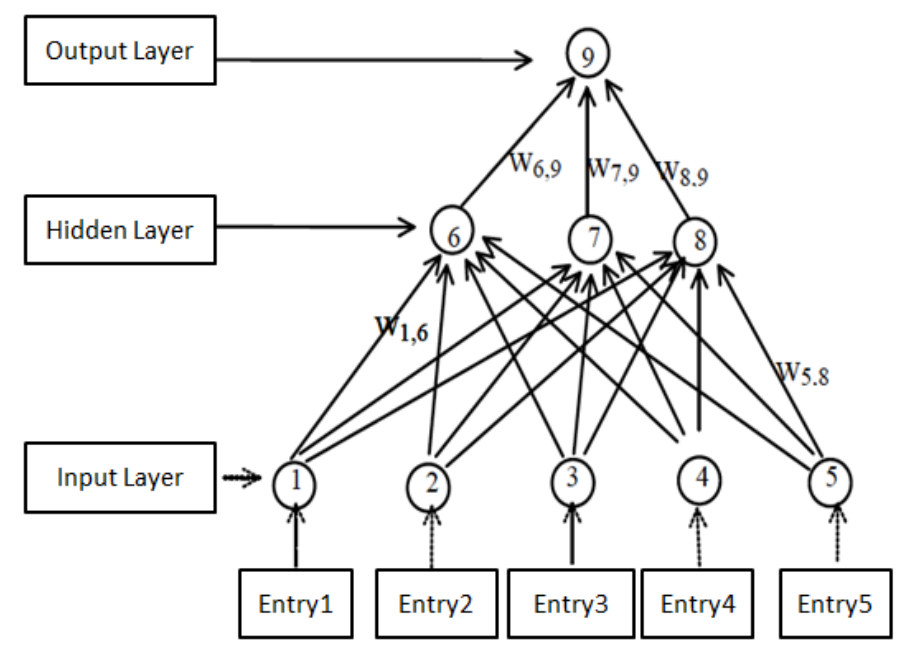

Figure 1. Architecture of a layered neural network 
Each neuron collects the outputs provided by the neurons of the preceding layer to determine its activation potential. The latter is then converted by an activation function in an output potential sent to the next layer of neurons. Each function increasing and odd can be selected but the most commonly used is the sigmoid function. The neural network training is based on the back propagation algorithm that adopts an iterative gradient descend method to minimize a cost function represented by the sum of errors to the square produced by the network with respect to the expected outputs (Hinton et al., 1986). The cost function mentioned above is used to determine the changes to be made to the synaptic weights at the next training epoch. The use of multiple hidden layers may lead to a too advanced fitting that decreases the generalization capabilities of the neural network although it increases the training performances (Paquet, 1997). After determining the network architecture, its implementation requires three data samples. The first set of data is used for the training, the second for the validation and the third is used to evaluate the generalization capabilities of the network. Beyond a certain number of iterations, the error committed on the validation sample no longer decreases and the network specializes in the training data. The weights corresponding to the lowest error on the validation sample are used to assess the capacity of the network to correctly classify the test sample that has never been presented to the neural network before.

The neural network is been realized using Matlab software.

\section{Results}

\subsection{Correlations and descriptive statistics}

Table 1 presents the correlations between the variables that have been introduced into the neural network. We may remark that all the correlations are under 0.5 and that independent variables have Variance Inflating Factors (VIF) under the value of 10 . With these tests, we do conclude that we have no important issue regarding the correlation between explanatory variables.

Table 1. Correlation matrix for explanatory variables

\begin{tabular}{llllll}
\hline & & VIF & $\mathbf{1}$ & $\mathbf{2}$ & $\mathbf{3}$ \\
\hline $\mathbf{1}$ & Solvency & 1.25 & 1 & & \\
$\mathbf{2}$ & Liquidity & 1.13 & 0.34 & 1 & \\
$\mathbf{3}$ & Profitability & 1.12 & 0.33 & 0.12 & 1 \\
\hline
\end{tabular}

Descriptive statistics are reported in table 2. Descriptive statistics regarding solvency, liquidity and profitability ratios are mentioned for the entire sample, for the group of bankrupt businesses and, finally, for the group of healthy businesses.

Table 2. Descriptive Statistics

\begin{tabular}{lcccc}
\hline & \multicolumn{2}{c}{ Total sample } & Bankrupted & Healthy \\
\hline & Mean & Std. Dev. & Mean & Mean \\
Solvency & 13.63 & 37.18 & -5.61 & 32.87 \\
Liquidity & 1.85 & 4.96 & 0.90 & 2.81 \\
Profitability & 13.32 & 50.48 & -2.06 & 28.70 \\
\hline
\end{tabular}

The analysis of the descriptive statistics (table 2) makes it possible to highlight some differences between the two groups of firms to discriminate (the group of bankrupt businesses and the group of healthy businesses). First, let us notice that the solvency ratio is quite different for the two subsamples. The mean value of the solvency ratio is negative for the group of bankrupt businesses (mean $=-5.61$ ); this means that these businesses have negative equity. For the group of healthy businesses, the mean value of the solvency ratio is positive (mean $=32.87$ ). The mean value of the liquidity ratio is much smaller for the group of bankrupt businesses (mean $=-0.90$ ) than for the group of healthy businesses (mean $=2.81$ ). Let us also notice that the value of this ratio is inferior to the value of 1 for the group of bankrupt businesses; this means that the businesses of this group cannot face their short term obligations. Regarding the profitability ratio, the mean value of the ratio EBIT/total assets is negative for the group of bankrupt businesses (mean $=-2.06$ ); this means that bankrupt businesses make, on average, no profits. For the group of healthy businesses, the mean value of the profitability ratio is positive $($ mean $=28.70)$.

\subsection{Neural network}

The results of the neural network aiming to discriminate between bankrupt and healthy firms are briefly presented in this section. The next session will discuss the findings in detail. The results of the neural network are shown in Table 3. 
Table 3. Neural network (dependent variable: bankruptcy)

\begin{tabular}{lllll}
\hline & Observations & Status & Percentage of good predictions & Percentage of incorrect predictions \\
\hline Training & 2,609 & Healthy & $74.50 \%$ & $25.50 \%$ \\
& & Bankrupt & $83.60 \%$ & $16.40 \%$ \\
Validation & \multirow{2}{*}{373} & Healthy & $82.70 \%$ & $17.30 \%$ \\
& \multirow{2}{*}{ Test } & Bankrupt & $77.60 \%$ & $22.40 \%$ \\
& \multirow{2}{*}{746} & Healthy & $69.90 \%$ & $30.01 \%$ \\
& & Bankrupt & $81.50 \%$ & $18.50 \%$ \\
\hline
\end{tabular}

The total sample of businesses has been split into three parts: 70 percent of the observations make part of the training group, 10 percent of the data form the validation group and 20 percent of the observations are used for the test. The neural network has first been trained with 2,609 observations. On this training subsample, the percentage of good predictions reached 83.60 percent for the bankrupt businesses; this means that, using this neural network, 83.60 percent of the bankrupted firms are correctly classified. The misclassification rate for bankrupt firms is therefore 16.4 percent. The trained neural network is, in a second step, tested on a second subsample of 746 businesses. On the test subsample, the percentage of good predictions reached 81.50 percent for the bankrupt businesses; this means that, using this neural network, 81.50 percent of the bankrupted firms are correctly classified. The misclassification rate for bankrupt firms is therefore 16.4 percent for the test subsample.

\section{Discussion and conclusion}

Bankruptcy prediction is a very important topic for different groups of people, especially for managers, lenders, investors who want to avoid bankruptcy because it would cause major problems for their companies. Aiming to predict the bankruptcy probability of Belgian Small and Medium Enterprises (SME's) over the period 2002-2012, we developed a neural network. We utilized a database from Bureau Van Dijk comprising 3,728 Belgian SME's among which 1,854 were declared bankrupt between 2002 and 2012. Because our objective is to create a "user friendly" way to discriminate between bankrupt and healthy businesses, we choose, as explanatory factors, three simple, uncorrelated and easily accessible ratios. These ratios are "equity/total assets" for the solvency, the current ratio for the liquidity and, finally "net income/total assets" for profitability. Then, we analyzed the data via the descriptive statistics and the results of the neural network. As per the descriptive statistics, it appears that solvency, liquidity and profitability ratios are very different between the two groups (healthy and bankrupt) of businesses. As expected, the group of healthy businesses shows much better mean values for these variables. Regarding the results of the neural network performed with Matlab sotfware, it appears that the good classification rate for the bankrupt businesses of this tool is higher than $80 \%$, even when testing the neural network on a separate sample. This result is higher than the one reported by Murtaza \& Shah (2000) and a bit lower than the one reported by Abou-Seada et al. (2005). Nevertheless, we used fewer ratios to discriminate between bankrupt and healthy businesses. Moreover, solvency, liquidity and profitability are simple and easily available financial ratios, even for small businesses. Finally, these ratios appear to be good predictors of bankruptcy. This result is in line with our hypothesis stating that these ratios are variables that allow discriminating between bankrupt and healthy businesses.

This study has some limitations. First, our analysis has been led on a particular country; a similar model could therefore be tested on different countries to strengthen our conclusions. Second, as this model takes into account financial ratios only, it does not take the specificities inherent to each firm into consideration. This study may be of interest for financial institutions who are interested by the bankruptcy of their clients. Academics may also be interested by the results of this study because the methodology that is used is uncommon in the Belgian literature regarding bankruptcy prediction.

\section{References}

Abou-Seada, M., Becerra, V., \& Galvao, R. (2005). Neural and wavelet network models for financial distress classification. Data Mining and Knowledge Discovery, 11, 35-55. http://dx.doi.org/10.1007/s10618-005-1360-0

Akers, M., Bellovary, J., \& Giacomino, D. (2007). A Review of Bankruptcy Prediction Studies : 1930 to present. Journal of Financial Education, 33(5), 1-42.

Alam, P., Booth, D, \& Lee, K. (2005). A comparison of supervised and unsupervised neural Networks in predicting bankruptcy of Korean firms. Expert Systems with Applications, 29, 1-16. http://dx.doi.org/10.1016/j.eswa.2005.01.004 
Altman E.I., Marco, G. \& Varetto, F. (1994). Corporate distress diagnosis: Comparisons using linear discriminant analysis and neural networks. Journal of Banking and Finance, 18(3), 505-529. http://dx.doi.org/10.1016/0378-4266(94)90007-8

Altman, E. (1968). Financial ratios, discriminant analysis \& the prediction of corporate bankruptcy. The Journal of Finance, 23(4), 589-609. http://dx.doi.org/10.1111/j.1540-6261.1968.tb00843.x

Beaver, W. (1966). Financial ratios as predictors of failures. Journal of Accounting Research, Empirical Research in Accounting: Selected Studies 1966, 71-111. http://dx.doi.org/10.2307/2490171

Bhabra, G.S., Premachandra, I.M., \& Sueyoshi, T. (2009). DEA as a tool for bankruptcy assessment: a comparative study with logistic regression technique. European Journal of Operational Research, 193(2), 412-424. http://dx.doi.org/10.1016/j.ejor.2007.11.036

Daubie, M., \& Meskens, N. (2001). Bankruptcy Prediction : Literature Survey of the Last Ten Years. Belgian Journal of Operational Research, Statistics and Computer Science, 41(1-2), 43-58.

Declerc M., Heins B. \& Van Wymeersch C. (1992). Flux financiers et prévision de faillite : une analyse comportementale de l'entreprise. Cahiers Economiques de Bruxelles, 136, 415-443.

Hinton' G., Rumelhart, D., \& Williams, R. (1986). Learning representations by back-propagating errors. Nature, 323 , 533 - 536. http://dx.doi.org/10.1038/323533a0

Hu, Y.C. \& Tseng, F.M. (2010). Comparing four bankruptcy prediction models: Logit, quadratic interval logit, neural and fuzzy neural networks, Expert Systems with Applications, 37, 1846-1853. http://dx.doi.org/10.1016/j.eswa.2009.07.081

Hu, M. Y, Indro, D. C., Patuwo, B. E, \& Zhang, G. (1999). Artificial neural networks in bankruptcy prediction: general framework and cross validation analysis. European Journal of Operational Research, 116, 16-32. http://dx.doi.org/10.1016/S0377-2217(98)00051-4

Kim, M.J., \& Kang, D.K. (2010). Ensemble with neural networks for bankruptcy prediction. Expert Systems with Applications, 37(4), 3373-3379. http://dx.doi.org/10.1016/j.eswa.2009.10.012

Lee, K. (2001). Pattern classification and clustering algorithms with supervised and supervised neural networks in financial applications. Ph.D. dissertation: Kent State University.

Murtaza, M., \& Shah, J. (2000). A neural network based clustering procedure for bankruptcy prediction. American Business Review, 18 (2), 80-86.

Odom, M., \& Sharda, R. (1990). A neural network model for bankruptcy prediction. Proceedings of the IEEE International Conference on Neural Network, 2, 163-168.

Ohlson, J. (1980). Financial ratios, \& the probabilistic prediction of bankruptcy. Journal of Accounting Research, 18(1), 109-131. http://dx.doi.org/10.2307/2490395

Ooghe, H., \& Verbaere, E. (1982). Determinant van faling: verklaring en predictie. Working paper, Rijksuniversiteit Gent.

Ooghe, H., Spaenjers, C., \& Vandermoere, P. (2005). Business failure prediction: simple-intuitive models versus statistical models. Working paper, Universiteit Gent.

Paquet, P. (1997). L'utilisation des réseaux de neurones artificiels en finance. Working paper University of Orleans.

Platt, M, Platt, H., \& Yang, Z. (1999). Probabilistic neural networks in bankruptcy prediction. Journal of Business Research, 44, 67-74. http://dx.doi.org/10.1016/S0148-2963(97)00242-7

Refait, C. (2004). La prévision de la faillite fondée sur l'analyse financière de l'entreprise : un état des lieux. Economie, \& prévision, 162(1), 129-147.

Zmijewski, M. (1984). Methodological issues related to the estimation of financial distress prediction models. Journal of Accounting Research, 22, Studies on Current Econometric Issues in Accounting Research, 59-82. 